\title{
膝伸展運動における最大等尺性収縮中の 内側広筋の筋活動の比較
}

\author{
Comparison of Muscle Activities of the Vastus Medialis Obliquus during Maximum \\ Isometric Contraction in Knee Extension Exercises
}

\author{
三秋 泰一 ${ }^{1)}$ 大角 久美子 ${ }^{2)}$ 楠戸 翔 ${ }^{3)}$ 荒井 貴裕 ${ }^{4)}$ \\ HIROICHI MIAKI ${ }^{1)}$, KUMIKo OSUMI ${ }^{2)}$, TsUBASA KUSUDO ${ }^{3)}$, TAKAHIRO ARAI ${ }^{4)}$ \\ 1) Division of Health Sciences, Graduate School of Medical Science, Kanazawa University: 11-80 Kodatsuno 5, Kanazawa, \\ Ishikawa 920-0942, Japan.TEL+81 76-265-2621 E-mail:miaki@mhs.mp.kanazawa-u.ac.jp \\ ${ }^{2)}$ Department of Rehabilitation, Kanazawa Red Cross Hospital \\ ${ }^{3)}$ Department of Rehabilitation, Kanazawa University Hospital \\ 4) Doctoral Course of Rehabilitation Science, Division of Health Sciences, Graduate School of Medical Science, Kanazawa \\ University
}

Rigakuryoho Kagaku 27(5): 553-557, 2012. Submitted Apr. 9, 2012. Accepted May 12, 2012.

\begin{abstract}
Purpose] The purpose of this study was to investigate the preferential activity of the vastus medialis oblique (VMO) of six isometric knee extension exercises. [Subjects] Eighteen healthy females participated in this study. [Methods] The subjects performed six isometric knee extension exercises: straight leg raise (SLR), straight leg raise with externally rotated hip, knee flexed at 60 degrees combined with neutral, internal, and external tibial rotation, and simultaneous isometric hip adduction at 10 degrees of hip adduction with the knee fully extended. The muscle activities of VMO and VL and VMO/VL ratios were calculated during the exercises. [Results] The VMO/VL ratios of the exercises with tibial rotations were significantly greater than the exercises involving SLR. VMO muscle activities of the exercises with tibial rotations were significantly higher than these of the other exercises. [Conclusion] The results suggest that isometric knee extension exercises with the knee flexed are effective at preferentially activating VMO. It will be necessary to examine the effect on preferential activity of VMO in knee extension exercises with the knee flexed.
\end{abstract}

Key words: vastus medialis oblique, $\mathrm{VMO} / \mathrm{VL}$ ratio, isometric exercise

要旨：〔目的〕6種類の最大膝伸展等尺性運動における内側広筋斜頭（VMO）の優先的活動の違いを検討した。〔対 象〕健常女性 18 名〔方法〕従来の下肢伸展挙上（SLR）, 股関節最大外旋位での SLR, 膝関節 $60^{\circ}$ 屈曲位で脛骨中 間位, 最大外旋位, 最大内旋位での膝関節伸展および股関節 $10^{\circ}$ 内転位での股関節内転の 6 種類の等尺性運動中の $\mathrm{VMO}$, 外側広筋 (VL) の筋活動量と VMO/VL 比を求めた。〔結果〕2 種類の SLR より脛骨回旋を伴った膝伸展運 動の $\mathrm{VMO} / \mathrm{VL}$ 比が有意に高かった. VMO の筋活動量は脛骨回旋を伴った 3 種類の膝伸展運動が他の 3 種類の運動 より有意に高かった。〔結語〕VMOの優先的活動としては滕屈曲位からの膝伸展運動の有効性が示唆された. 今後, 膝伸展運動（膝屈曲位）での練習効果の検証が必要である.

キーワード : 内側広筋斜頭, $\mathrm{VMO} / \mathrm{VL}$ 比, 等尺性運動

1) 金沢大学医薬保健研究域保健学系リハビリテーション科学領域: 金沢市小立野 5-11-80 (テ 920-0942) TEL 076-265-2621

2) 金沢赤十字病院 リハビリテーション科

3) 金沢大学附属病院 リハビリテーション部

4) 金沢大学大学院 医学系研究科 博士後期課程

受付日 2012年4月9日＼cjkstart受理日２012年5月12日 


\section{I.はじめに}

下肢の整形外科疾患に扮いて, 荷重や負荷抵抗をかけ られない場合, 大腿四頭筋の筋活動量は減少し, 廃用性 の筋力低下をきたす。このような場合，大腿四頭筋に対 する筋力増強運動として, 端座位での膝関節伸展運動や 下肢伸展挙上，大腿四頭筋セッティング（QS）等の等尺 性収縮運動が用いられる。特に内側広筋は筋萎縮を起こ しやすく回復しにくいといわれている1)。また，内側広 筋斜頭 $(\mathrm{VMO})$ は, 膝関節の保護や支持性に重要な役割 を担うほか, 膝蓋骨の外側偏位を抑止する特異的な機能 がある ${ }^{2)}$ ．また，段差昇降では内側広筋の外側広筋 $(\mathrm{VL})$ の筋活動比が 1 以上となり歩行時より高い3)という報告 もあり，VMOをより優位に活動させることは膝蓋骨車 脱臼の予防や階段昇降時においては重要なことである. また，矢形4) はVMOを優位に活動させる運動とは $\mathrm{VMO}$ の筋活動が高值を示すか否かは問題ではなく，内 側広筋の外側広筋に対する活動比率 (VMO/VL比) が高 值を示す運動を意味すると述べている.

$\mathrm{VMO}$ の優先的収縮に関する報告は, 股関節内転を伴 う膝伸展運動が VMO/VL比を上げるとした報告5,6)があ る一方で股関節内転運動を行ってもVMOの筋活動量は QS と同じであったとする報告もある7)。下腿や股関節 の回旋を伴う膝伸展運動についても同様に回旋方向によ り $\mathrm{VMO} / \mathrm{VL}$ 比に影響があるという報告 8,9$)$ と, ないとい う報告があり 10,11$)$ ，一定の見解が得られていない． そこで, 本研究の目的は, 最大等尺性収縮での Open Kinetic Chain (OKC) 運動の方が多関節運動である
Closed Kinetic Chain 運動より大腿四頭筋に対して高い 筋活動が期待できると考えられるために OKC 運動での $\mathrm{VMO}$ の優先的活動に影響があるとされているおもな運 動間でどの運動が VMOの優先的活動に最も影響を与え るのかを検証することとした

\section{II. 対象と方法}

1. 対象

被験者は，あらかじめ測定手段，運動方法を十分に説 明し，実験に同意を得られた両下肢に整形外科的疾患の 既往がない健常女性 18 名とした，平均年齢は $22.9 \pm 2.9$ 歳, 平均身長は $161.9 \pm 6.8 \mathrm{~cm}$, 平均体重 $52.9 \pm 3.2 \mathrm{~kg}$ であった。

2. 方法

1) 運動方法 (図 1)

測定脚は非利き脚とした。運動方法は, 次に述べる 6 種類とし, 最大等尺性収縮でそれぞれ 5 秒間 3 回行った。 各試行の間に 60 秒間の休息を入れた。

（1）非測定脚の膝関節を $60^{\circ}$ 屈曲位とした仰臥位で, 測定脚の足関節角度は任意とし股関節内外転 - 内外旋中 間位で, 股関節屈曲 $60^{\circ}$ の位置で停止するよう外果上に かけたベルトで調整した状態での下肢伸展拳上運動 (SLR).

（2）非測定脚の膝関節を $60^{\circ}$ 屈曲位とした仰臥位で, 測定脚の足関節角度は任意とし股関節内外転中間位 - 最 大外旋位で股関節屈曲 $60^{\circ}$ の位置で停止するよう外果上

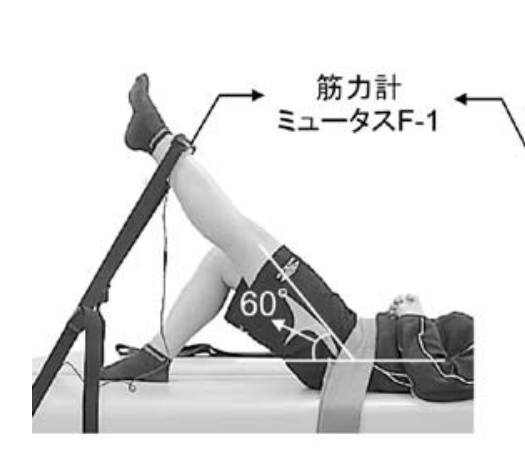

(1) SLR (2) SLR股外旋

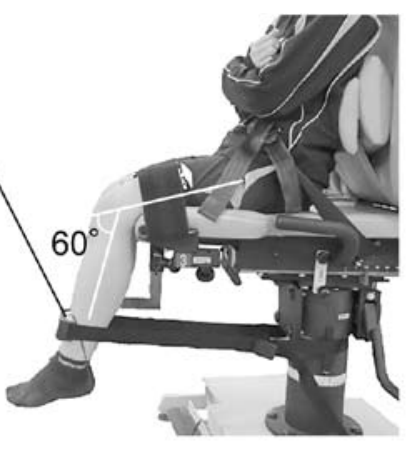

(3) 伸展中間位

(4) 伸展外旋位

(5) 伸展内旋位

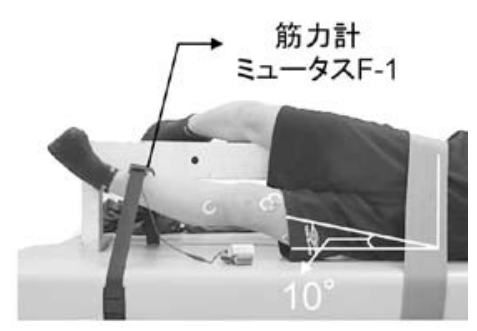

(6) 股内転

SLR : 非測定脚の膝関節を $60^{\circ}$ 屈曲位とし, 股関節内外転 · 内外旋中間位で, 股関節屈曲 $60^{\circ}$ での下肢伸展拳上 運動

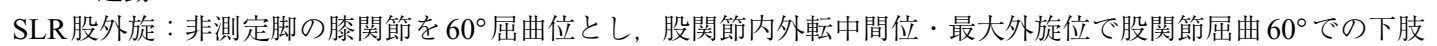
伸展拳上運動

伸展中間位：脛骨内外旋中間位で膝関節屈曲 $60^{\circ}$ での膝関節伸展運動

伸展外旋位：脛骨最大外旋位で膝関節屈曲 $60^{\circ}$ での膝関節伸展運動

伸展内旋位：脛骨最大内旋位で膝関節屈曲 $60^{\circ}$ での膝関節伸展運動

股内転 : 膝関節完全伸展位で大腿四頭筋の等尺性収縮を行わせながら股関節内転 $10 \circ の$ 位置での股関節内転運動

図1運動方法 
にかけたベルトで調整した状態での下肢伸展拳上運動 (SLR股外旋).

（3）椅座位で，足関節角度は任意とし脛骨内外旋中間 位で，膝関節屈曲 $60^{\circ}$ の位置で停止するよう外果上にか けたベルトで調整した状態での膝関節伸展運動（伸展中 間位)

（4）椅座位で, 足関節角度は任意とし脛骨最大外旋位 で, 膝関節屈曲 $60^{\circ}$ の位置で停止するよう外果上にかけ たベルトで調整した状態での膝関節伸展運動（伸展外旋 位).

（5）椅座位で，足関節角度は任意とし脛骨最大内旋位 で，膝関節屈曲 $60^{\circ}$ の位置で停止するよう外果上にかけ たベルトで調整した状態での膝関節伸展運動（伸展内旋 位).

（6）測定脚を下にした側臥位で，膝関節完全伸展位で 大腿四頭筋の等尺性収縮を行わせながら股関節内転 $10^{\circ}$ の位置で停止するよう外果上にかけたベルトで調整した 状態での股関節内転運動 (股内転).

測定肢位における関節角度は股関節については東大式 ゴニオメーター, 膝関節については電子角度計 $(\mathrm{SG}-150$ ； 株式会社DKH）を用いて設定した。骨盤の固定にはべル トを用いた。

2）筋力測定

股内転を除く（1）〜（5）のそれぞれの運動中における 最大等尺性筋力を膝伸展筋力としてミュータス F-1（アニ マ株式会社)を用い測定した。測定はミュータスF-1を外 果上に置き 3 回行った。 3 回中の最大值をそれぞれの運 動方法での膝伸展最大筋力とした。
3）筋電図測定方法

表面筋電図 (EMG) は，6種類の運動およびQSにおけ る最大等尺性収縮中に測定した，QSは，仰臥位にて膝 完全伸展位とし，そのまま最大随意努力にて大腿四頭筋 の等尺性収縮を 5 秒間保持させ，その時の EMG 測定 した，筋電図の記録には AP1000（株式会社デジテックス 研究所製）を用い，筋電信号およびトリガー信号を A/D 変換装置にて 16 bit で $\mathrm{A} / \mathrm{D}$ 変換し, パーソナルコンピュー ター内に記録した。サンプリング周波数は $1000 \mathrm{~Hz}$ とし バンドパスフィルターは $10 \mathrm{~Hz} \sim 500 \mathrm{~Hz}$ とした，測定筋 は大腿直筋 $(\mathrm{RF}), \mathrm{VMO}, \mathrm{VL}$ の3筋とし, 双極誘導法 により筋活動電位を導出した。電極の入力抵抗を $5 \mathrm{k} \Omega$ 以下とした後, 銀一塩化銀のディスポーザブル電極 Blue sensor（P-00-S；Ambu）を貼付した. 電極貼付部位は, VMOについては膝蓋骨上縁より $4 \mathrm{~cm}$ 上方かつ $3 \mathrm{~cm}$ 内 側を中心として大腿骨長軸より内側に $55^{\circ}$ 傾いた直線上, VLは膝蓋骨上縁より $10 \mathrm{~cm}$ 上方かつ $6 \mathrm{~cm}$ 外側を中心と して大腿骨長軸より外側に $10^{\circ}$ 傾いた直線上に電極間距 離を $2.5 \mathrm{~cm}$ で貼付した ${ }^{12)}$. RF は Basmajian ${ }^{13)}$ の推奨す る部位に貼付した。

4) データ解析

EMGは，それぞれの運動において最大筋力を発揮し た試行について解析した。解析にはBIMUTAS II（キッ セイコムテック株式会社）を用い, 入力されたトリガー 信号から 5 秒間の筋電図波形をもとに最初と最後の 1 秒 間を除く中央の 3 秒間の実効值 (RMS 值)を $30 \mathrm{~ms}$ 毎に算 出し, その算出された RMS 值の平均 RMS 值を求めた. 運動方法間での筋活動量を比較するために各運動中の筋 活動量の正規化を行った。正規化は根地嶋ら9)や

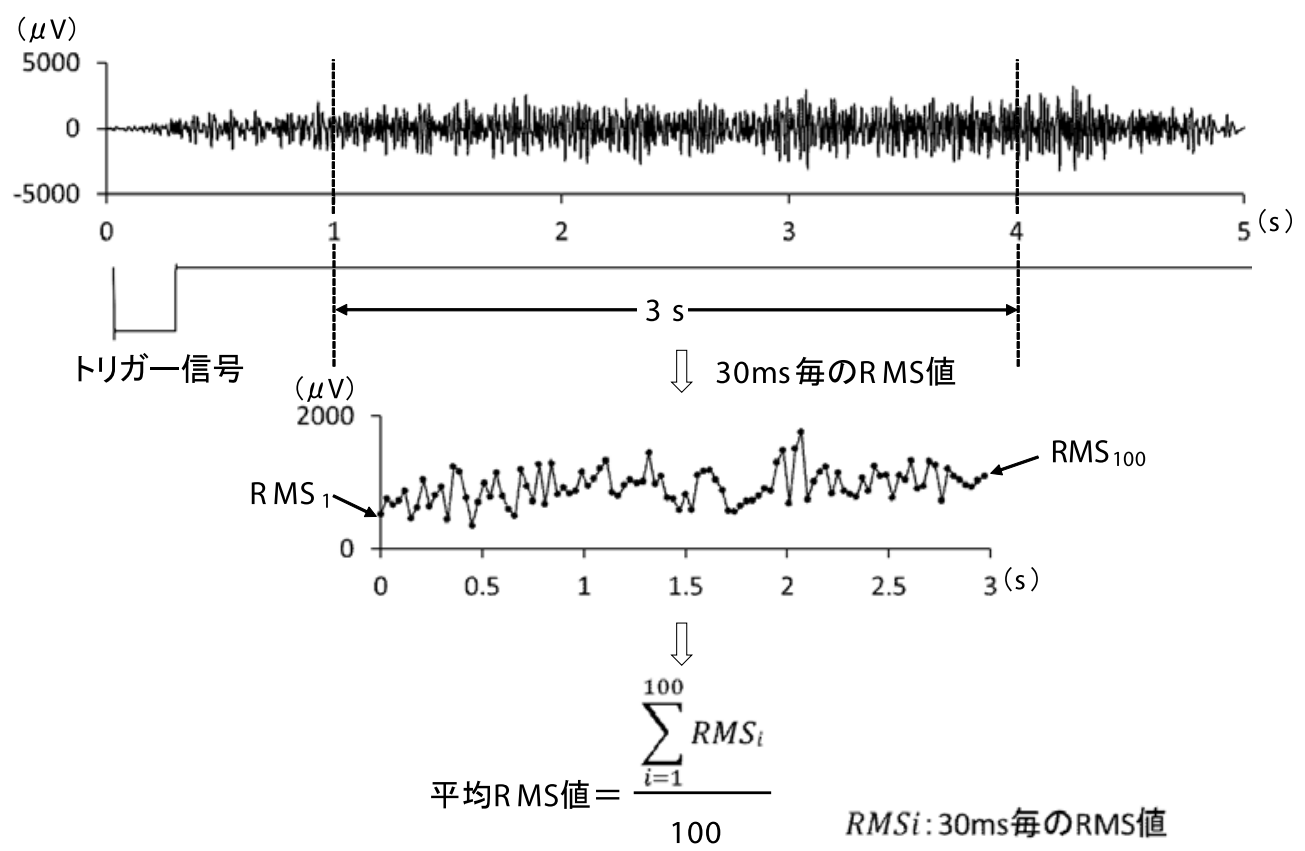

図2 EMGデー夕処理方法 
Browyerら 14)の方法をもとに各運動中の平均 RMS 值を QSにおける平均 RMS 值で除すことで行った。 そして, VMOの正規化された筋活動量をVLの正規化された活 動量で除し，VMO/VL比を算出した（図2).

5) 統計分析

$\mathrm{VMO} / \mathrm{VL}$ 比および筇活動量の運動方法間の比較は一 元配置分散分析後, 事後検定として対応のある $\mathrm{t}$ 検定を 用いBonferroniの補正を行った。 なお，有意水準は5\% 未満とした。

\section{III. 結 果}

膝伸展最大筋力は, SLR, SLR外旋位に比較して伸展 外旋位, 伸展内旋位, 伸展中間位の方が有意に大きかっ た（ $\mathrm{p}<0.0001 ）($ 表 1$) . S L R$ SLR 外旋位との間および 伸展外旋位, 伸展内旋位, 伸展中間位の 3 群間の間には 有意差は認められなかった。

$\mathrm{VMO} / \mathrm{VL}$ 比（表2）は，伸展中間位 $(1.60 \pm 0.52)$ が SLR $(1.10 \pm 0.42), \quad$ SLR 外旋位 $(0.98 \pm 0.36)$ より有意 に高值を示した $(\mathrm{p}<0.05, \mathrm{p}<0.01)$. 伸展内旋位 $(1.49 \pm$ $0.60)$ および伸展外旋位 $(1.41 \pm 0.53)$ はSLR外旋位より 有意に高值を示した $(\mathrm{p}<0.05)$. 股内転のVMO/VL比 (1.29 $\pm 0.40 ）$ は, 伸展中間位, 伸展内旋位, 伸展外旋位に次 いで高い值を示したが, どの運動方法との間にも有意差 は認められなかった.SLRとSLR外旋位との間には有意 差は認められなかった。 また, SLRと伸展内旋位, 伸展 外旋位との間にも有意差は認められなかった。

表 1 運動種目別膝伸展最大筋力

\begin{tabular}{lc}
\hline \multicolumn{1}{c}{ 運動方法 } & 筋力 $(\mathrm{kg})$ \\
\hline SLR & $7.1 \pm 1.8$ \\
SLR 股外旋 & $5.8 \pm 1.6$ \\
伸展外旋位 & $37.5 \pm 8.9^{\# \dagger}$ \\
伸展中間位 & $41.8 \pm 7.8^{\# \dagger}$ \\
伸展内旋位 & $39.8 \pm 8.4^{\# \dagger}$ \\
\hline \#: SLR との比較 $(\mathrm{p}<0.0001)$ \\
${ }^{\dagger}: \mathrm{SLR}$ 股外旋との比較 $(\mathrm{p}<0.0001)$
\end{tabular}

表2 運動種目別 VMO/VL比

\begin{tabular}{ll}
\hline \multicolumn{1}{c}{ 運動種目 } & VMO/VL 比 \\
\hline SLR & $1.10 \pm 0.42$ \\
SLR 股外旋 & $0.98 \pm 0.38$ \\
股内転 & $1.29 \pm 0.37$ \\
伸展中間位 & $1.63 \pm 0.55 \# \dagger$ \\
伸展外旋位 & $1.41 \pm 0.53 \S$ \\
伸展内旋位 & $1.49 \pm 0.65 \S$ \\
\hline
\end{tabular}

*: SLR との比較 $(\mathrm{p}<0.05)$

$\S,{ }^{\dagger}:$ SLR 股外旋との比較 $\left(\S ; \mathrm{p}<0.05,{ }^{\dagger} ; \mathrm{p}<0.01\right)$
VMOの筋活動量（表3）はSLR で52.6 $\pm 18.3 \%$, SLR 股外旋で $51.0 \pm 30.9 \%$ ，股内転で $74.7 \pm 37.8 \%$ ，伸展 中間位で $232.0 \pm 114.9 \%$, 伸展外旋位で $180.7 \pm$ $111.9 \%$ ，伸展内旋位で $221.8 \pm 128.5 \%$ であった。運動 方法間の比較では，伸展中間位，伸展外旋位，伸展内旋 位におけるそれぞれの筋活動量は，SLR，SLR外旋，股 内転におけるそれぞれの筋活動量より有意に高かった $(\mathrm{p}<0.01)$. 伸展中間位, 伸展外旋位, 伸展内旋位での間 では，筋活動量に有意差は認められなかった，股内転の 筋活動量はどの運動方法とも有意差は認められなかった。

\section{IV. 考 察}

$\mathrm{OKC}$ 運動でVMOの優先的活動に影響があるとされ ている股関節外旋位での膝伸展運動, 股関節内転運動を 伴った膝伸展運動および下腿回旋を伴った膝伸展運動に おける VMOの筋活動比率を比較した。

本研究の結果, VMO/VL比およびVMOの筋活動量は, SLR, SLR股外旋より膝屈曲 $60^{\circ}$ での伸展外旋位, 伸展 内旋位, 伸展中間位の方が高く, 各運動時の最大膝伸展 筋力の比較ではSLR, SLR 股外旋より伸展外旋位, 伸 展内旋位，伸展中間位の方が有意に高かった。 Herrington ら 15) はVMO/VL比は筋に対する負荷量の高 い方が高いと報告している。また，VMOの筋活動量は， 膝関節伸展位付近より屈曲位の方が高いという報告があ る16)。これらのことより，VMOの優先的収縮のために はより大きい筋力が発揮できる膝屈曲位での膝伸展運動 の方が適していると考えられる。VMOは直接膝蓋骨内 側縁に付着しており，その線維方向が内側へ $50 \sim 55^{\circ}$ 傾 いている17)ことにより VMOは脛骨の内旋作用を有する と考えられ，脛骨を内旋させた状態がよりVMOを活動 させると予想した。 しかし, 伸展内旋位と伸展中間位, 伸展外旋位, との間にVMO/VL比の違いは認められなかっ た.これについては, 膝伸展に脛骨の内旋を組み合わせ

表 3 運動種目別 VMO $の$ 筋活動量

\begin{tabular}{|c|c|}
\hline 運動種目 & 筋活動量（\%) \\
\hline SLR & $52.6 \pm 18.3$ \\
\hline SLR股外旋 & $51.0 \pm 30.9$ \\
\hline 股内転 & $74.7 \pm 37.8$ \\
\hline 伸展中間位 & $232.0 \pm 114.9^{\dagger \S \emptyset}$ \\
\hline 伸展外旋位 & $180.7 \pm 111.9^{\dagger \S *}$ \\
\hline 伸展内旋位 & $221.8 \pm 128.5^{\dagger \S \text { ๆ }}$ \\
\hline
\end{tabular}

筋活動量 : quadriceps setting でのVMOの平均 RMS 值に対する比率

VMO : vastus medialis oblique

$\dagger:$ SLR との比較 $(\mathrm{p}<0.01), \S$ : SLR 股外旋との比 較 $(\mathrm{p}<0.01)$

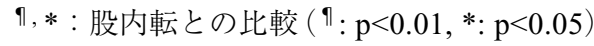


た最大等尺性収縮の方が膝伸展のみの最大等尺性収縮よ り VMO/VL 比が高かったという報告 ${ }^{8)}$ がある。しかし, 本研究では脛骨内旋方向には抵抗をかけておらず, 内旋 位を保持させるのみであり，内旋筋としてのVMOの収 縮が不十分であったと考えられる。

股関節内転運動を伴った膝伸展運動における $\mathrm{VMO} /$ VL 比は, 1.29 で 1 以上であり脛骨の回旋要素を組み合 わせた伸展中間位, 伸展外旋位, 伸展内旋位の膝伸展運 動との有意差は認められず, 同程度のVMO/VL 比を示 した。しかし，VMOの筋活動量は脛骨の回旋要素を組 み合わせた 3 種目の膝伸展運動より有意に低かった。こ れは，VMOがVLに比較し優先的に活動しているもの の筋活動量は脛骨回旋を加えた膝伸展最大等尺性収縮よ り低いため, 膝伸展位での膝伸展に股関節内転を組み合 わせた最大等尺性運動は優先的 VMO 収縮トレーニング としては不十分であると考えられる。

本研究の結果，より大きい膝伸展筋力が発揮できる膝 屈曲位の方が VMOの優先的収縮がえられることが示唆 された。しかし，膝伸展運動に脛骨の回旋と股関節内転 のどちらを組み合わせる方がVMOを優先的に活動させ るのかは言及できなかった，今後は，膝屈曲位での膝伸 展運動に股関節内転運動を加えた条件や回旋方向へ抵抗 を加えた条件および回旋角度による違いを検討する必要 がある。

\section{引用文献}

1) 市橋則明, 三宅裕子, 川原 勲・他：スポーツ外傷後の 大腿四頭筋筋委縮の一考察．PTジャーナル， 1994，28(3): 205-207.

2) Basmajian JV: Reeducation of vastus medialis: a misconception. Arch Phys Med Rehabil, 1970, 51(4): 245-247.

3) 笠原敏史, 鳥井勇輔, 高橋光彦 - 他 : 段差昇降の大腿四 頭筋の活動と床反力の関係．理学療法科学, 2009, 24(4): 523-528.

4) 矢形幸久：内側広筋優位の大腿四頭筋強化訓練に関する研 究.リ八医学, 1998, 35(8): 556-562.
5) Hanten WP, Schulthies SS: Exercise effect on electromyographic activity of the vastus medialis oblique and vastus lateralis muscles. Phys Ther, 1990, 70(9): 561-565.

6) Hodges PW, Richardson CA: The influence of isometric hip adduction on quadriceps femoris activity. Scand J Rehabil Med, 1993, 25(2): 57-62.

7) Zakaria D, Harburn KI, Kramer JF: Preferential activation of the vastus medialis oblique, vastus lateralis, and hip adductor muscles during isometric exercises in females. J Orthop Sports Phys Ther, 1997, 26(1): 23-28

8) Sousa A, Macedo R: Effect of the contraction of medial rotators of the tibia on the electromyographic activity of vastus medialis and vastus lateralis. J Electromyogr Kinesiol, 2010, 20(5): 967-972.

9) 根地嶋誠, 他 : 膝関節伸展位等尺性収縮時の股関節肢位と 内側広筋筋活動. 理学療法学, 2004, 31(6): 359-363.

10) Serrão FV, Cabral CMN, Bérzin F, et al.: Effect of tibia rotation on the electromyographical activity of the vastus medialis oblique and vastus lateralis longus muscles during isometric leg press. Phys Ther Sport, 2005, 6(1): 15-23.

11) Herrington L, Blacker M, Enjuanes N, et al.: The effect of limb position, exercise mode and contraction type on overall activity of VMO and VL. Phys Ther Sport, 2006, 7(2): 87-92.

12) Cowan SM, Bennell KL, Hodges PW, et al.: Delayed onset of electromyographic activity of vastus medialis obliquus relative to vastus lateralis in subjects with patellofemoral pain syndrome. Arch Phys Med Rehabil, 2001, 82(2): 183-189.

13) Basmajian JV: Biofeedback. Principles and for Clonicians. Williams and Wilkins, Baltimore, 1989, pp369-382.

14) Bowyer D, Armstrong M, Dixon J, et al.: The vastus medialis electromyographic intensity ratio does not differ by gender in young participants without knee pathology. Physiotherapy, 2008, 94(2): 168-173.

15) Herrington L, Pearson S: Does level of load affect relative activation levels of vastus medialis oblique and vastus laterialis? J Electromyogr Kinesiol, 2006, 16(4): 379-383.

16) Brownstein BA, Lamb RL, Mangine RE: Quadriceps torque and integrated electromyography. J Orthop Sports Phys Ther, 1985, 6(6): 309-314.

17) Peeler J, Cooper J, Porter MM, et al.: Structural parameters of the vastus medialis muscle. Clinical Anatomy, 2005, 18(4): 281-289. 